\title{
Anatomical basis for cell transplantation into mouse seminiferous tubules
}

\author{
Unai Silván ${ }^{1,2}$ and Juan Aréchaga ${ }^{1,2}$ \\ ${ }^{1}$ Laboratory of Stem Cells, Development and Cancer, Department of Cell Biology and Histology and ${ }^{2}$ Biomedical High \\ Resolution and Analytical Microscopy Core Facility, Faculty of Medicine and Dentistry, University of the Basque \\ Country, E-48940 Leioa, Vizcaya, Spain
}

Correspondence should be addressed to J Aréchaga at Laboratory of Stem Cells, Development and Cancer, Department of Cell Biology and Histology, Faculty of Medicine and Dentistry, University of the Basque Country; Email: juan.arechaga@ehu.es

U Silván is now at Biozentrum, University of Basel, Basel, Switzerland

\begin{abstract}
Cell transplantation into the seminiferous tubules is a useful technique for the study of physiological and pathological conditions affecting the testis. However, the precise three-dimensional organization and, particularly, the complex connectivity of the seminiferous network have not yet been thoroughly characterized. To date, the technical approaches to address these issues have included manual dissection under the stereomicroscope, reconstruction of histological serial sections, and injection of contrast dyes, but all of them have yielded only partial information. Here, using an approach based on the microinjection of a self-polymerizing resin followed by chemical digestion of the surrounding soft tissues, we reveal fine details of the seminiferous tubule scaffold and its connections. These replicas of the testis seminiferous network were studied by scanning electron microscopy. The present results not only establish a morphological basis for more precise microinjection into the mouse seminiferous tubules but also enable a more profound investigation of physiological and embryological features of the testis.

Reproduction (2012) 144 385-392
\end{abstract}

\section{Introduction}

Mouse adult testicles are ovoid organs that weight around $150 \mathrm{mg}$ and have an average size of $8.5 \times 5 \mathrm{~mm}$. Gametogenesis occurs inside the seminiferous tubules, which contain the pluripotent germ cell niche, enclosed by Sertoli cells, the basal lamina, and the peritubular myoid cell layer. In this compartment, diploid spermatogonia undergo differentiation into spermatocytes through a complex process (Dym et al. 2009). The extraabdominal location of the testicles, together with their vascular heat exchanger and the reflex contraction of the cremaster muscle (that can retract the testes towards the abdomen in response to situations of cold or fear), permits the regulation of testicular temperature, so that it can be maintained constant at a slightly lower temperature than the rest of the body, what is crucial for spermatogenesis in mammals (Liu 2010).

Cell transplantation into the seminiferous tubules was initially developed in the mid 1990s (Brinster \& Zimmermann 1994). In these pioneering experiments, cell transplantation was achieved by microinjecting individual seminiferous tubules; however, this method rarely results in the complete filling of the testicular network. Later on, two improved experimental approaches were described, namely microinjection into the rete testis and through the efferent ducts (Ogawa et al. 1997). Although these new methods remarkably increase transplantation efficiency, the lack of knowledge of the morphology of the involved structures frequently results in the accidental rupture of the membranes lining them. This invariably leads to the extravasation of the cell solution out of the intratubular compartment and consequently to transplantation failure. We believe that a more precise knowledge of the anatomy of the testis will be very helpful for improving the efficacy of transplantation into the seminiferous tubules.

Using this technique, it was shown that germinal cells from one animal transplanted into the seminiferous tubules of another were able to incorporate into the seminiferous epithelium of the recipient testis and differentiate into fertilization-competent spermatozoa. Until now, several different cell types have been used in transplantation experiments including adult spermatogonia (Brinster \& Avarbock 1994, Avarbock et al. 1996, Clouthier et al. 1996, Dobrinski et al. 1999, Ogawa et al. 1999, 2000, Li et al. 2010), primitive germinal cells and 
gonocytes (Jiang \& Short 1998), embryonic stem cells (Silván et al. 2009, 2010, 2011), bone marrow stem cells (Lue et al. 2007), Sertoli cells (Shinohara et al. 2003), and seminoma and embryonal carcinoma cell lines (Li et al. 2008).

The anatomy of the testis has been extensively studied since the XVII century (De Graaf 1668) mainly in mammals, including humans, using light and electron microscopy. Manual dissection, reconstruction of serial histological sections, and microinjection of dyes have revealed differences in the structures that conform this organ between several mammal species (Roosen-Runge 1961, Dym 1976, Cavicchia \& Burgos 1977, RoosenRunge \& Holstein 1978, Wrobel 2001, Wrobel \& Schimmel 2001). However, none of these techniques precisely described the three-dimensional architecture of the seminiferous tubule network and of the seminal drainage system of the testis. Nevertheless, a precise knowledge of these networks is required for the detection and characterization of possible abnormalities caused by genetic or acquired diseases that may contribute to infertility (Hsieh et al. 2010).

Here, we report a detailed morphological description of the murine testis, based on the microinjection of a self-polymerizing resin into the seminiferous tubules. As all seminiferous tubules and the efferent ducts are interconnected, the resin filled the entire lumen of the testis including its excretory system. Later, following resin polymerization and chemical digestion of the tissues surrounding the cast, a replica of the threedimensional network of the mouse testis tubules was obtained. Its analysis under the scanning electron microscope, and comparison with histological sections and dye-microinjected samples of the same regions, revealed valuable details of the seminiferous tubule scaffold and its connections with other ducts.

\section{Results}

Here, we describe the casts, tracing the same path followed by spermatozoa after their complete differentiation, from the seminiferous tubules to the efferent ducts, paying special attention to the less known structures. All measurements were made directly on the resin casts; only small differences with in vivo data are expected.

The bulk of the testis volume is occupied by the convoluted seminiferous tubules (Fig. 1A and B, Supplementary Movie 1, see section on supplementary data given at the end of this article), which have a mean approximate diameter of $110 \mu \mathrm{m}$. These tubules do not have blind endings and rarely exhibit bifurcations (Fig. 1C). At high magnification, the tracks left by the tails of immature spermatids can be observed on the surface of the casts, with their heads embedded in the cytoplasm of Sertoli cells (Fig. 1D).
Both ends of the seminiferous tubules, just before entering the rete testis, are connected to the straight tubules (tubuli recti) showing an abrupt constriction at the level of the junction (Fig. 2A). This narrow communication bridge has an approximate length of $50 \mu \mathrm{m}$ and a variable diameter that ranges between 15 and $45 \mu \mathrm{m}$. However, although the size of all constrictions in a given cast is similar, there is high variability between samples (Fig. 2B and C). Optical microscopy images confirmed that this final portion of the seminiferous tubules has a smaller diameter than the convoluted seminiferous tubules and shows slight thickenings of the peritubular myoid layer (Fig. 2D). After these narrow bridges, the straight tubules recover the same diameter of the convoluted tubules and drain into the rete testis.

Corrosion casting of the testis reveals a new view of the so-called rete testis, which is not a network ('rete' in Latin means 'net') but rather a flat reservoir with an approximate size of $400 \times 600 \mu \mathrm{m}$ located close to the mediastinum testis, through which the blood vessels penetrate the organ. However, this structure shows some variability in shape and size between specimens (Fig. 3A and B). Standard histological analysis reveals its proximity to the tunica albuginea, the slimness of its wall and its location under the vascular pediculum of the testis (Fig. 2D). At high magnification, nuclear imprints of the cells forming the walls of the cavity can be appreciated on the surface of the casts (Fig. 3D). Manual dissection of the corrosion casts under the stereomicroscope allowed us to view the bottom part of the rete testis and facilitated the observation of the seminiferous tubules that reach this structure.

The extratesticular rete testis (area cribrosa) appears as a small vaulted protrusion sticking out from the tunica albuginea that connects the intratesticular rete testis with the efferent ducts. This structure has an approximate diameter of $130 \mu \mathrm{m}$ and a height of $200 \mu \mathrm{m}$ (Fig. 4A) and shows multiple holes of variable sizes, ranging from 20 to $60 \mu \mathrm{m}$ in diameter. This particular area is hardly interpretable in equivalent histological sections (Fig. 4B).

The efferent ducts (ductuli efferentes) emerge from the extratesticular rete testis. These channels, which lead spermatozoa to the epididymis, can be easily seen in vivo at stereomicroscope low magnification after microinjection of trypan blue dye (Fig. 4C). In turn, corrosion casting offers a detailed image of the duct structure and of their connection with the testis (Fig. 4D). The analyzed testicles had between two to five efferent ducts each, and their shape and diameter was very irregular, with an average of $50 \mu \mathrm{m}$. Occasionally, a distended portion of one of the efferent ducts could be seen in both in vivo specimens and in corrosion casts (Fig. 4C and D). Histological analysis revealed that these ducts exhibit increasing diameters as they move away from the rete testis to the epididymis (Fig. 4E). 

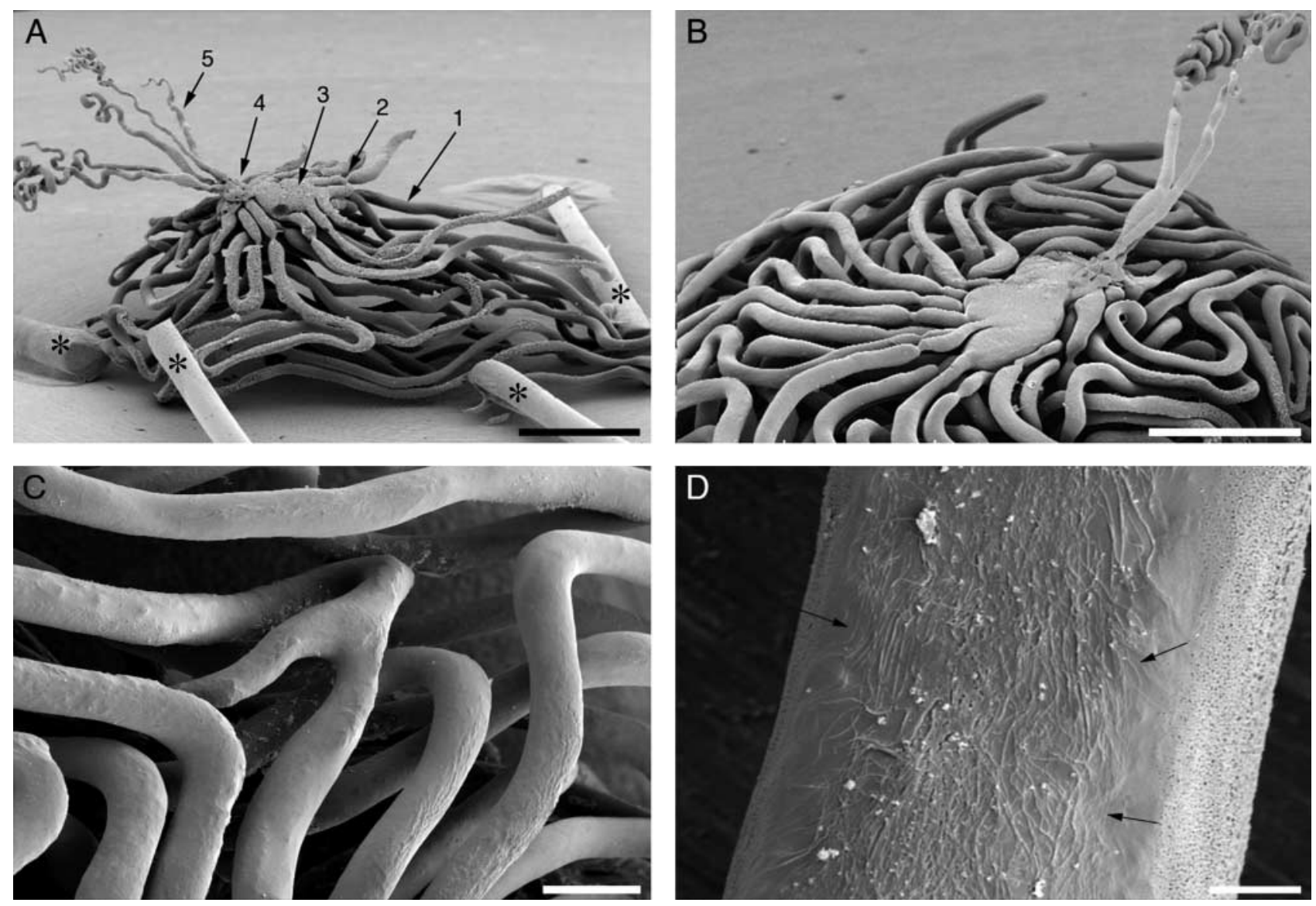

Figure 1 Corrosion casts of the murine testis. (A) Lateral overview of a corrosion cast of the whole mouse testis under low-power scanning electron microscopy in which we can recognize (1) the convoluted seminiferous tubules, (2) the straight tubules, (3) the intratesticular rete testis, (4) the extratesticular rete testis, and (5) the efferent ducts. Some convoluted tubules broke during preparation, due to the fragility of the corrosion cast. The copper wires used as conductive bridges can be observed $(*)$. (B) Cranial overview of another cast of the seminiferous network. (C) The seminiferous tubules appear as a convoluted network of tubes, which rarely bifurcate. (D) At higher magnification, the imprints left by the tails of spermatids on the surface of the resin can be seen (arrows). This is indicative of good filling of the tubules with the resin. Scale bars represent $1 \mathrm{~mm}$ in A, $750 \mu \mathrm{m}$ in B, $200 \mu \mathrm{m}$ in C, and $20 \mu \mathrm{m}$ in D.

\section{Discussion}

Although cell transplantation into the mouse seminiferous tubules is a widely used technique for the study of germ cell differentiation and germinal cancer invasion processes (Parreira et al. 1998, Li et al. 2008, 2010, Silván et al. 2009, 2010, 2011), the high-resolution anatomy of the seminiferous tubule network and its connections has never been precisely described. This knowledge would facilitate the transplantation technique and more in-depth analysis of the obtained results. In order to overcome this limitation, we have developed a new approach to study in detail the three-dimensional organization of the seminiferous tubule network by microinjecting a self-polymerizing resin into the seminiferous tubules followed by chemical digestion of the surrounding tissues.

The injection of self-polymerizing resins into hollow spaces of organs and tumors is a broadly used technique, especially in the study of blood and lymphatic capillaries
(Ohtani \& Ohtani 2008, Silván et al. 2009). When employed in the study of testis anatomy, this approach resulted in replicas of the testicular luminal spaces that could be visualized under the scanning electron microscope. The presence of cell imprints on the surface of the obtained corrosion casts is indicative of the complete filling of the seminiferous network with the resin and, thus, minimizes the possibility of artifacts caused by defective casting. As a complement for the interpretation of the casts, we performed microinjection of dyes and routine histological sections of normal murine testis.

There are two types of intratesticular tubules: the 'convoluted' tubules (seminiferous tubules, strictly speaking) and the 'straight' tubules (tubuli recti), and the epithelial wear of both is different (Supplementary Figure 2 (see section on supplementary data given at the end of this article); Osman 1978, Osman \& Plöen 1978). In the straight tubules, this epithelium has a simple cuboidal form, without germinal cells (Dym 1974), and this characteristic points to a possibly distinct 

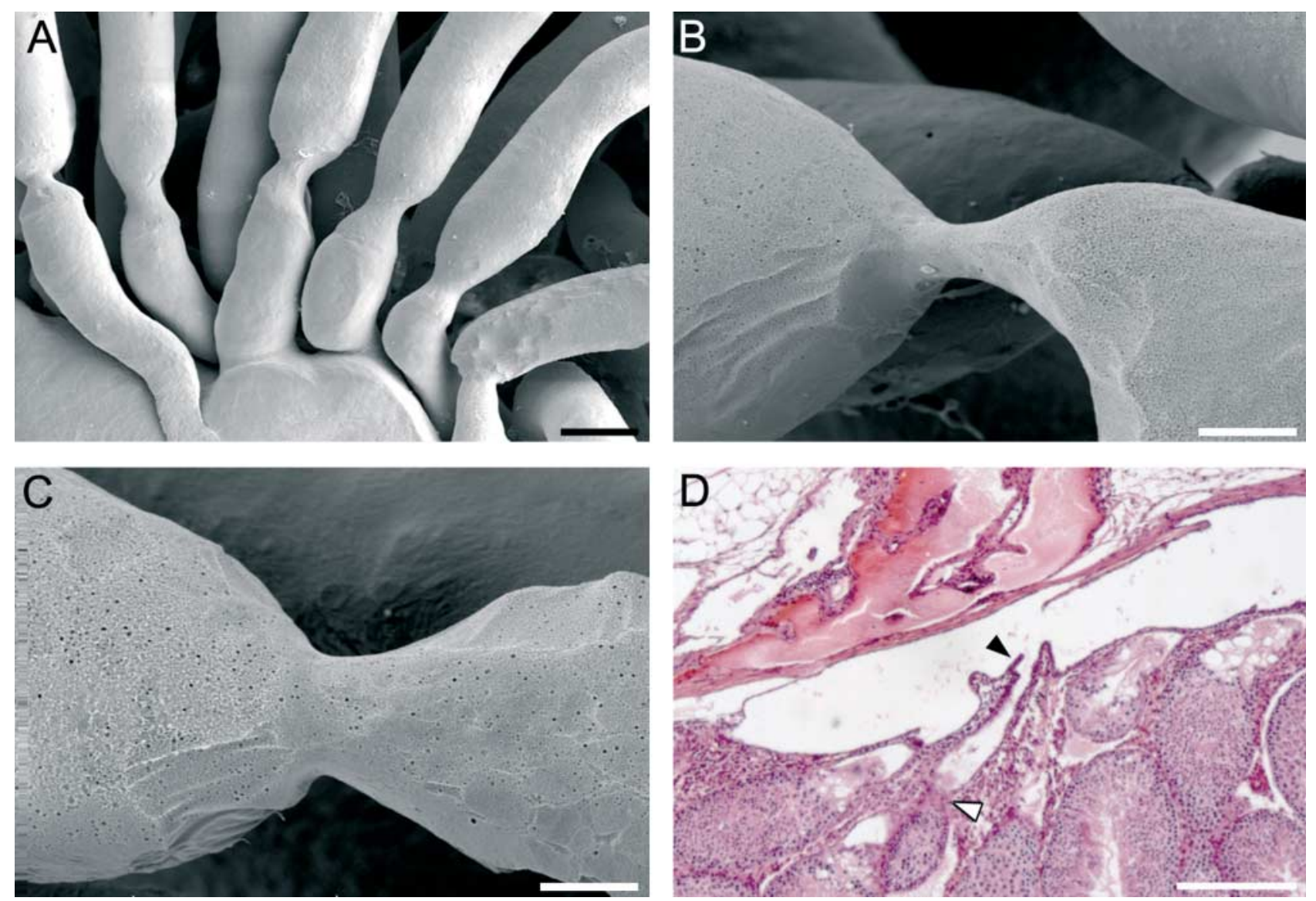

Figure 2 Connection of straight and convoluted tubules. (A) Corrosion casting of the connection of straight and convoluted tubules reveals a constriction with similar diameter in a given testis, but with high variability between specimens ( $\mathrm{B}$ and $\mathrm{C}$ ). This feature corroborates the existence of a possible sphincter mechanism at this level. (D) The same region observed using routine histology exhibits narrowing (white arrowhead) and of a valve-like structure in the region in which the tubules connect with the rete testis (black arrowhead). Scale bars represent $100 \mu \mathrm{m}$ in $\mathrm{A}$ and $\mathrm{B}$ and $25 \mu \mathrm{m}$ in $\mathrm{C}$ and $\mathrm{D}$.

embryological origin of both kinds of tubules, from the mesonephros and the genital ridges respectively. The convoluted seminiferous tubules, lining by the germinal epithelium, represent the vast majority of the testis volume and constitute the location where spermatogenesis takes place. In the corrosion casts, which we obtained, the seminiferous network is seen as a dense bunch of tubules that rarely bifurcate and that have both endings connected to the straight tubules.

In the connection between the two types of tubules, a sudden narrowing of the tubule diameter is found. Interestingly, the diameter of this constriction seems to be subject dependent, with differences of up to $30 \mu \mathrm{m}$ between casts. The functional significance of the narrowing of the tubules is not clear. As spermatozoa do not acquire mobility until their maturation in the epididymis (Russell et al. 1990), peristaltic contractions of the smooth muscle cell layer surrounding the seminiferous tubules are needed to transport these cells (Wrobel et al. 1986, Yamamoto et al. 1989). Thus, we speculate that the narrowing may be a sphincter that can open and close to avoid spermatozoa backflow. In fact,
Cavicchia \& Burgos (1977) reported that the ligation of the efferent ducts results in a dilation of the rete testis and straight tubules, with the effect on the seminiferous tubules being less significant. Later on, Wrobel (2001) suggested two different systems, peritubular contractile cells and vascular plexus, as possible mechanisms to close the tubules. Our histological analysis of this region supports the idea that myoid cells are responsible for a sphincter-like action; however, a complementary valve-like action of the terminal portion of the straight tubules cannot be ruled out (Fig. 2A). Corrosion casts also reveal that the straight and convoluted tubules have similar diameters. The narrow connection between both testis tubules may underlie the less efficient filling of the seminiferous network when microinjection is performed through individual seminiferous tubules (Silván et al. 2011).

The exact location where the mammalian urogenital junction (the union between the primitive sex cords of the male genital ridges and mesonephric Wolffian ducts) takes place is an issue of debate (Wrobel 2001). For instance, it has previously been reported that in bovid 

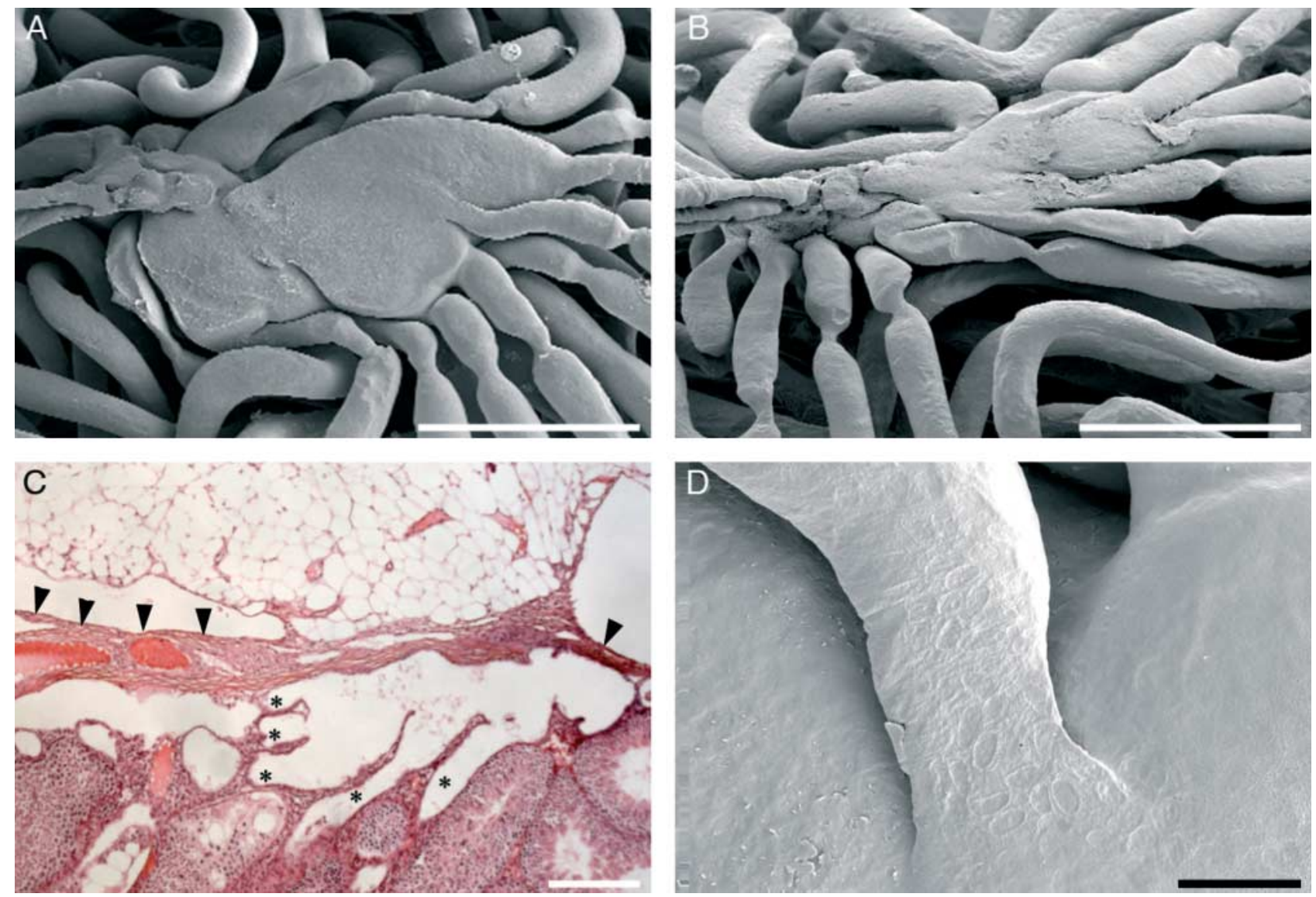

Figure 3 The intra- and extratesticular rete testis. (A and B) The shape of this 'reservoir chamber' (lacuna testis) shows variability between specimens. (C) Light microscopy revealed the position of the intratesticular rete testis under the tunica albuginea (arrowheads) and its slimness. The connection of several straight tubules can also be observed (asterisks). (D) Cell nuclei imprints from the coating epithelium of a straight tubule ending in the intratesticular rete testis, indicative of resin good filling. Scale bars represent $500 \mu \mathrm{m}$ in A and B, $100 \mu \mathrm{m}$ in C, and $50 \mu \mathrm{m}$ in D.

embryos, this event occurs at the level of the extratesticular rete testis (Hinton \& Turner 1988, Wrobel \& Schimmel 2001). However, histological analysis of adult mice shows dramatic epithelium changes in the region where convoluted and straight tubules are connected (Fig. 2D). This fact suggests that, at least in mice, this area may be the site where the urogenital junction occurs. Nonetheless, further studies during mouse embryogenesis are needed to resolve this question.

Straight tubules (tubuli recti) end in a structure termed the rete testis (the meaning of rete in Latin is net), which in the mouse consists of two portions: one intra- and one extratesticular. Nevertheless, it is known that the location and morphology of this structure varies among species, being 'cavitary' and 'superficial' in rodents (Dym 1974). In fact, corrosion casts and histological images show that the intratesticular portion of the murine rete testis is a reservoir-like structure that could be more appropriately named lacuna testis (reservoir in English). This structure is located immediately under the tunica albuginea, which makes it easy to use for cell transplantation (Ogawa et al. 1997, Silván et al. 2011). The most evident function of the rete testis is to act as a collection chamber in which all the seminiferous tubules release spermatozoa on their way out of the testis. An evident advantage of the term lacuna testis over rete testis is that the seminal fluid produced by all seminiferous tubules is mixed, and thus homogenized, before it continues its journey to the epididymis. Although the shape of the intratesticular rete testis is highly variable, its superficial position under the vascular pediculum, together with its generally large size, makes it easy to find. However, the structure is very thin, and if the micropipette is not inserted almost parallel to the surface of the testis, it is possible to pierce the compartment leading to the delivery of the solution in the testis stroma. Thus, when performing transplantation using this path, short and sharp pipettes have to be used and the applied pressure has to be carefully controlled.

Close to the mediastinum testis, where the vascular supply penetrates the organ, the extratesticular portion of the rete testis is found. The morphology of this structure is hardly distinguishable using routine histology. In contrast, corrosion casts show it as a small vaulted protrusion located on the testis surface, in a peripheral position to the lacuna testis. The extratesticular rete testis 

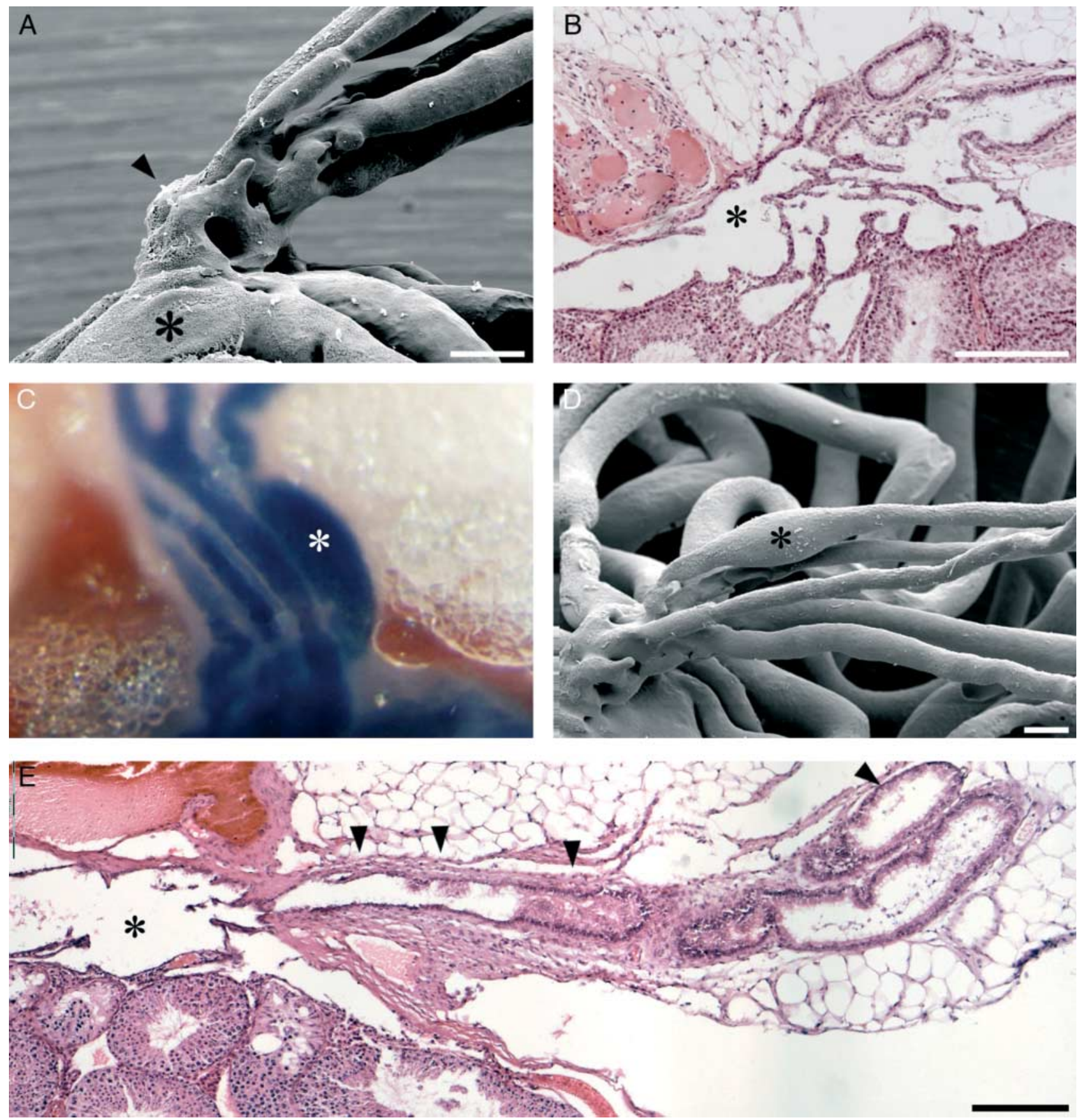

Figure 4 The extratesticular rete testis and efferent duct connections. (A) Corrosion casting reveals the existence of several holes in the extratesticular rete testis (arrowhead). This structure connects the intratesticular rete reservoir (white asterisk) with the efferent ducts (asterisk). (B) Histological section at the same level confirms the irregularity of this structure and the vicinity of blood capillaries (asterisk). (C) In vivo image of the efferent ducts leaving the rete testis filled with trypan blue solution (asterisk: dilated duct). (D) An equivalent area as seen in corrosion casts. Note a similar distension (asterisk) in an efferent duct and the variable sizes of these channels. (E) Histological section at the level of the rete testis (asterisk) and the emerging efferent ducts (arrowheads). All scale bars represent $100 \mu \mathrm{m}$.

is a pierced structure, although the precise function of its holes remains unclear. One possibility is that these piercings are due to blood capillaries, which warm the seminal fluid before it enters into the collecting ducts. As the interchange of molecules and spermiophagocytic activity are two functions of the rete testis epithelium
(Sinowatz et al. 1979), an increased contact surface, just like that resulting from the cavities found in the extratesticular rete, may be required. Thus, it is possible that in mice, the larger contact surface resulting from the holes present in this structure subserves the molecular interchange function. 
From the extratesticular rete, a variable number of efferent ducts emerge. They run in parallel to each other and show very irregular shapes and frequent dilatations or swellings indicative of high flexibility, a functional characteristic that would reduce spermatozoa backflow. In addition to their connecting role, the efferent ducts are responsible for fluid reabsorption and protein synthesis and secretion (Crabo 1965, Jiang \& Short 1998). In this regard, it has been suggested that $90 \%$ of the fluid passing through these ducts is reabsorbed to concentrate the spermatozoa suspension (Levine \& Marsh 1971). Efferent duct walls are lined internally with a single epithelium layer composed of two cell types, ciliated and non-ciliated. When using this path for cell transplantation, one has to take into account the existence of the extratesticular rete testis at the end of the ducts. If the micropipette is too deeply inserted and reaches this intricate structure, its lining membrane could be damaged and the cell solution extravasated. Another complication associated with this method is the thickness of the connective walls surrounding the efferent ducts, which makes cannulation difficult.

The results we present here establish the anatomical basis for cell transplantation into the seminiferous tubules and facilitate the localization of the testicular structures involved in the described microinjection approaches. As the laboratory mouse plays a central role in biomedical research, being used as primary model in fields like cancer, aging, diabetes, development, among others, we believe that a more precise knowledge of its testicular morphology is essential for further interpretation of associated pathologies. Moreover, the technique that we report here may also be useful for the characterization of anatomical abnormalities in the testis of animals with acquired or genetic diseases.

\section{Materials and Methods}

Borosilicate glass pipettes with an approximate tip diameter of $50 \mu \mathrm{m}$ were connected to a $10 \mathrm{ml}$ plastic syringe by polyethylene tubing and the whole system was filled with a fresh mixture of Mercox CL-2B resin and Mercox polymerization accelerator (Vilene Med., Tokyo, Japan) at variable proportions. Adult Swiss mice (OF1, IFA CREDO, Barcelona, Spain) were killed and the testes were removed from the abdominal cavity, pinned to a dissection plate, and microinjected with the above resin mixture as described in detail elsewhere (Ogawa et al. 1997, Silván et al. 2011) until the filling of the seminiferous network was complete. Then, the testes were immersed for $1 \mathrm{~h}$ in a $40^{\circ} \mathrm{C}$ water bath to accelerate the polymerization of the resin. Subsequently, the organs were submerged in a $5 \%$ potassium hydroxide solution that was changed daily until the soft tissues surrounding the testis casts had disappeared. Specimens were washed with abundant distilled water, dehydrated, and mounted on conductive stubs, using thin copper wires as conductive bridges. Finally, samples were gold coated using a SCD 040 Balzers Union sputtercoater. The testis casts were visualized and photographed using Philips ESEM XL30 and Hitachi S-3400N scanning electron microscopes. For further details on corrosion cast preparation, see the monograph by Aharinejad \& Lametschwandtner (1997).

To study the seminiferous network system in vivo, we microinjected diluted solutions of trypan blue or bromophenol blue (both at $0.005-0.01 \% \mathrm{w} / \mathrm{v}$ ) and viewed the testis using an optical stereomicroscope (Leica MZ Apo). Testes were analyzed as well by standard histological techniques. Briefly, testes were fixed overnight in Bouin's fixative, routinely processed, and embedded in paraffin blocks. Sections $(5 \mu \mathrm{m}$ thick) were stained with hematoxylin and eosin and photographed using light microscopy (Leica, DAS Mikroskop DMR). All protocols and procedures with live animals were carried out in accordance with current European regulations and approved by the Animal Welfare and Ethics Committee of the University of the Basque Country (CEBA/197/2011 and CEBA/168/2010).

\section{Supplementary data}

This is linked to the online version of the paper at http://dx.doi. org/10.1530/REP-12-0043.

\section{Declaration of interest}

The authors declare that there is no conflict of interest that could be perceived as prejudicing the impartiality of the research reported.

\section{Funding}

Research grants from the Spanish Ministry of Education and Science (BFU 2007-66610), Basque Government (IT560-10) and SPRI/Saiotek program to J Aréchaga supported this work. U Silván had a pre-doctoral fellowship from the University of the Basque Country.

\section{Acknowledgements}

The authors would like to express their thanks to Prof. Dr M A Konerding, Dr A Carretero, and Dr A Rodriguez-Baeza for their advice with the corrosion casting technique and to Dr D Fogarty and Mr J L Vidaurrázaga for critical reading and editorial assistance.

\section{References}

Aharinejad SH \& Lametschwandtner A 1993 Microvascular Corrosion Casting in Scanning Electron Microscopy: Techniques and Applications. New York: Springer.

Avarbock MR, Brinster CJ \& Brinster RL 1996 Reconstitution of spermatogenesis from frozen spermatogonial stem cells. Nature Medicine 2 693-696. (doi:10.1038/nm0696-693)

Brinster RL \& Avarbock MR 1994 Germline transmission of donor haplotype following spermatogonial transplantation. PNAS 91 11303-11307. (doi:10.1073/pnas.91.24.11303) 
Brinster RL \& Zimmermann JW 1994 Spermatogenesis following male germ-cell transplantation. PNAS 91 11289-11302. (doi:10.1073/pnas. 91.24.11298)

Cavicchia JC \& Burgos MH 1977 Tridimensional reconstruction and histology of the intratesticular seminal pathway in the hamster. Anatomical Record 187 1-10. (doi:10.1002/ar.1091870102)

Clouthier DE, Avarbock MR, Maika SD, Hammer RE \& Brinster RL 1996 Rat spermatogenesis in mouse testis. Nature 381 418-421. (doi:10.1038/ 381418a0)

Crabo B 1965 Studies on the composition of epididymal content in bulls and boars. Acta Veterinaria Scandinavica 22 1-94.

De Graaf R 1668 De virorum organis generationi inservientibus, de clÿsteribus et de usu siphonis in Anatomia. Ex Officina Hackiana, Leiden and Rotterdam.

Dobrinski I, Avarbock MR \& Brinster RL 1999 Transplantation of germ cells from rabbits and dogs into mouse testes. Biology of Reproduction 61 1331-1339. (doi:10.1095/biolreprod61.5.1331)

Dym M 1974 The fine structure of monkey Sertoli cells in the transitional zone at the junction of the seminiferous tubules with the tubuli recti. American Journal of Anatomy 140 1-25. (doi:10.1002/aja.1001400102)

Dym M 1976 The mammalian rete testis - a morphological examination. Anatomical Record 186 493-523. (doi:10.1002/ar.1091860404)

Dym M, Kokkinaki M \& Zuping H 2009 Spermatogonial stem cell: mouse and human comparisons. Birth Defects Research (Part C) 87 27-34. (doi:10.1002/bdrc.20141)

Hinton BT \& Turner TT 1988 Is the epididymis a kidney analogue? News in Physiological Science 3 28-31.

Hsieh MH, Hollander A, Lamb DJ \& Turek PJ 2010 The genetic and phenotypic basis of infertility in men with pediatric urologic disorders. Urology 76 25-31. (doi:10.1016/j.urology.2010.03.011)

Jiang FX \& Short RV 1998 Different fate of primordial germ cells and gonocytes following transplantation. Acta Pathologica, Microbiologica et Immunologica 106 58-63. (doi:10.1111/j.1699-0463. 1998.tb01319.x)

Levine N \& Marsh DJ 1971 Micropuncture studies of the electrochemical aspects of fluid and electrolyte transport in individual seminiferous tubules, the epididymis and the vas deferens in rats. Journal of Physiology 213 557-570.

Li Y, Kido T, Lu J, Fukuda M, Dobrinski I \& Lau YF 2008 Intratubular transplantation as a strategy for establishing animal models of testicular germ cell tumors. International Journal of Experimental Pathology $\mathbf{8 9}$ 342-349. (doi:10.1111/j.1365-2613.2008.00611.x)

Li J, Savolainen H, Tan F \& Zheng S 2010 Orthotopic testicular transplantation in mice. Reproduction 139 447-452. (doi:10.1530/ REP-08-0464)

Liu YX 2010 Temperature control of spermatogenesis and prospect of male contraception. Frontiers in Bioscience 1 730-755. (doi:10.2741/s97)

Lue Y, Erkkila K, Liu PY, Ma K, Wang C, Hikim AS \& Swerdloff RS 2007 Fate of bone marrow stem cells transplanted into testis: potential implication for men with testicular failure. American Journal of Pathology 170 899-908. (doi:10.2353/ajpath.2007.060543)

Ogawa T, Aréchaga J, Avarbock MR \& Brinster RL 1997 Transplantation of testis germinal cells into mouse seminiferous tubules. International Journal of Developmental Biology 41 111-122.

Ogawa T, Dobrinski I, Avarbock MR \& Brinster RL 1999 Xenogenetic spermatogenesis following transplantation of hamster germ cells to mouse testes. Biology of Reproduction 60 515-521. (doi:10.1095/ biolreprod60.2.515)

Ogawa T, Dobrinski I, Avarbock MR \& Brinster RL 2000 Transplantation of male germ line stem cells restores fertility in infertile mice. Nature Medicine 6 29-34. (doi:10.1038/71496)
Ohtani O \& Ohtani Y 2008 Lymph circulation in the liver. Anatomical Record 291 643-652. (doi:10.1002/ar.20681)

Osman DI 1978 On the ultrastructure of modified Sertoli cells in the terminal segment of seminiferous tubules in the boar. Journal of Anatomy 127 603-613.

Osman DI \& Plöen L 1978 The mammalian tubuli recti: ultrastructural study. Anatomical Record 192 1-17. (doi:10.1002/ar.1091920102)

Parreira GG, Ogawa T, Avarbock MR, França LR, Brinster RL \& Russell LD 1998 Development of germ cell transplants in mice. Biology of Reproduction 59 1360-1370. (doi:10.1095/biolreprod59.6.1360)

Roosen-Runge EC 1961 The rete testis in the albino rat: its structure, development and morphological significance. Acta Anatomica 45 1-30. (doi:10.1159/000141738)

Roosen-Runge EC \& Holstein AF 1978 The human rete testis. Cell and Tissue Research 189 409-433. (doi:10.1007/BF00209130)

Russell LD, Ettlin RA Hikim APS \& Clegg ED 1990 Mammalian spermatogenesis. In Histological and Histopathological Evaluation of the Testis, 1st edn, pp 1-38. Eds LD Russell, RA Ettlin, APS Hikim \& ED Clegg. Clearwater: Cache River Press.

Shinohara T, Orwig KE, Avarbock M \& Brinster RL 2003 Restoration of spermatogenesis in infertile mice by Sertoli cell transplantation. Biology of Reproduction 68 1064-1071. (doi:10.1095/biolreprod.102.009977)

Silván U, Arlucea J, Andrade R, Díez-Torre A, Silió M, Konerding MA \& Aréchaga J 2009 Angiogenesis and vascular network of teratocarcinoma from embryonic stem cell transplant into seminiferous tubules. British Journal of Cancer 101 64-70. (doi:10.1038/sj.bjc.6605125)

Silván U, Díez-Torre A, Jiménez-Rojo L \& Aréchaga J 2010 Vascularization of testicular germ cell tumours: evidence from experimental teratocarcinomas. International Journal of Andrology 33 765-774. (doi:10.1111/ j.1365-2605.2010.01068.x)

Silván U, Díez-Torre A, Andrade R, Arluzea J, Silió M \& Aréchaga J 2011 Embryonic stem cell transplantation into seminiferous tubules: a model for the study of invasive germ cell tumors of the testis. Cell Transplantation 20 637-642. (doi:10.3727/096368910X536581)

Sinowatz F, Wrobel KH, Sinowatz S \& Kugler P 1979 Ultrastructural evidence for phagocytosis of spermatozoa in the bovine rete testis and testicular straight tubules. Journal of Reproduction and Fertility 57 1-4. (doi:10.1530/jrf.0.0570001)

Wrobel KH 2001 Morphogenesis of the bovine rete testis: extratesticular rete, mesonephros and establishment of the definitive urogenital junction. Anatomy and Embryology 203 293-307. (doi:10.1007/s004290100162)

Wrobel KH \& Schimmel M 2001 Establishment of the urogenital junction in the male bovine embryo: an ultrastructural study. Anatomy and Embryology 204 225-237. (doi:10.1007/s004290100193)

Wrobel KH, Schilling E \& Zwack M 1986 Postnatal development of the connection between tubulus seminiferous and tubulus rectus in the bovine testis. Cell and Tissue Research 246 387-400. (doi:10.1007/ BF00215902)

Yamamoto M, Nagai T, Takaba H, Hashimoto J \& Miyake K 1989 In-vitro contractility of human seminiferous tubules in response to testosterone, dihydrotestosterone and estradiol. Urological Research 17 265-268. (doi:10.1007/BF00262608)

Received 3 February 2012

First decision 12 March 2012

Revised manuscript received 14 May 2012

Accepted 29 June 2012 